\title{
Laparoscopic management of large benign ovarian cysts
}

\author{
Ashwini Sidhmalswamy G. ${ }^{*}$, Jyoti S. Ghongdemath ${ }^{2}$ \\ ${ }^{1}$ Department of Obstetrics and Gynecology, Vydehi Institute of Medical Sciences and Research Centre, Bengaluru, \\ Karnataka, India \\ ${ }^{2}$ Consultant, Obstetrics and Gynecology, Vishwajyoti Nursing Home, Gokak, Karnataka, India
}

Received: 24 October 2017

Accepted: 17 November 2017

\section{*Correspondence:}

Dr. Ashwini Sidhmalswamy G.,

E-mail: ashnisg22@gmail.com

Copyright: (c) the author(s), publisher and licensee Medip Academy. This is an open-access article distributed under the terms of the Creative Commons Attribution Non-Commercial License, which permits unrestricted non-commercial use, distribution, and reproduction in any medium, provided the original work is properly cited.

\section{ABSTRACT}

Background: Laparoscopy has become an accepted method of management of ovarian cysts. Objective of present study was to assess the feasibility and outcome of laparoscopic surgery for the management of large ovarian cysts.

Methods: Ten patients from May 2014 to April 2015, with large ovarian cysts, with diameter $>10 \mathrm{~cm}$, were managed laparoscopically. All the masses were cystic and were not associated with ascites or enlarged lymph nodes on ultrasound. Serum CA 125 levels were within the normal range $(0-35 \mathrm{U} / \mathrm{mL})$. Preoperative evaluation included history, clinical examination, sonographic images and serum markers. The management of these ovarian cysts included aspiration, cystectomy or salphingo-oophorectomy, depending on the patient's age, obstetric history and desire of future fertility.

Results: Seven patients presented with pain abdomen, 3 patients with abdominal distension and discomfort. The average maximum diameter of the ovarian cysts was $14.75 \mathrm{~cm}$ (range, 10-22 cm). The mean duration of the operation was 80 minutes (60 -120 min). The postoperative hospital stay was 2 days. No intraoperative complications occurred, and the hospital course of all patients was uncomplicated. The patients did not report any complaints during follow-up and the clinical examination findings were normal in all, up to 9 months after discharge.

Conclusions: With proper patient selection, the size of an ovarian cyst is not necessarily a contraindication for laparoscopic surgery.

Keywords: Laparoscopy, Large benign ovarian cysts

\section{INTRODUCTION}

Ovarian cysts form part of gynecological disorders in females all over the world. They may occur at any age. Functional and inflammatory enlargements of the ovary develop almost exclusively during the child bearing years.

An ovarian tumour in adolescent and postmenopausal women is more often malignant than benign. The cysts may be asymptomatic or produce local discomfort, menstrual disturbances, infertility, or rarely cause acute symptoms due to complications like haemorrhage, rupture or torsion.
There is less scope for laparoscopy in treatment of solid ovarian masses. But laparoscopy has become an accepted method of management of ovarian cysts, when malignancy can be ruled out. While small cysts can be managed conservatively and the large ones by laparoscopy, the extremely large ovarian cysts present a major challenge for the endoscopic surgeon. Increased probability of malignancy, technical problems related to the removal of such cysts and peri-operative problems related to cardio-respiratory functional changes may complicate surgery for such cysts. ${ }^{1}$

Recent advances in endoscopic surgical techniques have offered new possibilities for laparoscopic treatment of 
large ovarian cysts. ${ }^{2} \mathrm{We}$ report our experience with 10 cases of large benign ovarian cysts, that were managed laparoscopically. ${ }^{3}$

\section{METHODS}

In a retrospective study, we evaluated 10 patients with large ovarian cysts, with low probability for malignancy, treated laparoscopically in our hospital between May 2014 to April 2015.

Inclusion criteria included large ovarian cyst with size more than $10 \mathrm{~cm}$, absence of ascites, absence of complex mass, without any evidence of intraperitoneal spread, no enlarged pelvic lymph nodes and normal serum tumor marker levels (CA125 < $35 \mathrm{U} / \mathrm{mL}$ ). In each case, informed consent was obtained, including a statement that laparotomy might be required if cancer was suspected intraoperatively or if the mass could not be properly managed by laparoscopy alone. All the operations were performed under general anesthesia.

Preoperative evaluation included history, clinical examination, sonographic images and serum markers. Large, solid, fixed or irregular adnexal masses suspicious of malignancy were not included in this study. CA-125 estimation was done for all women and $35 \mathrm{U} / \mathrm{ml}$ was taken as upper limit.

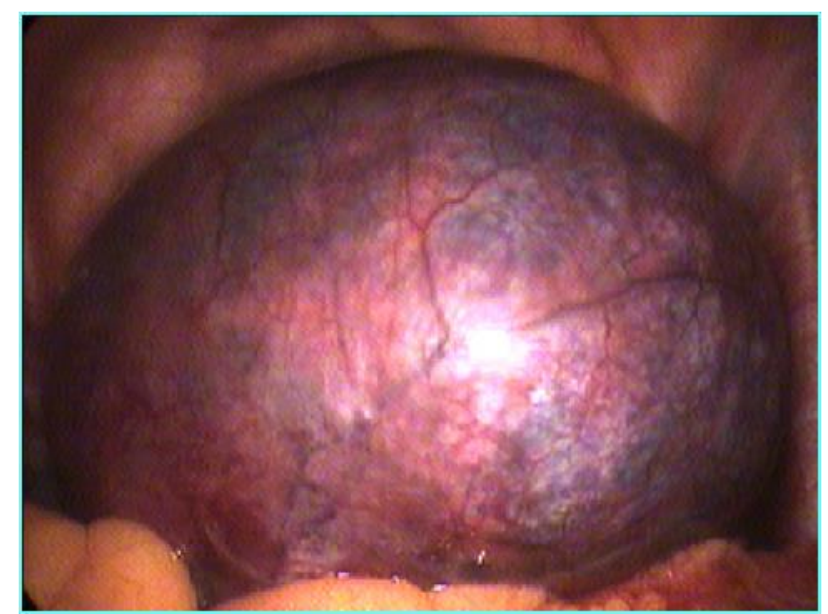

Figure 1: Visualisation of large ovarian cyst from primary port before placing lateral working ports.

For peritoneal access, open laparoscopy was done in all patients. An incision of about $1.5 \mathrm{~cm}$ at the umbilical or supraumbilical area or at palmer's point, depending on the size of the cyst, was made and dissection of abdominal layers was performed under vision until the peritoneal cavity was entered. The cyst visualized before creating the lateral ports (Figure 1). For extremely large cysts, primary port of $5 \mathrm{~mm}$ created, trocar and sleeve were introduced directly into the cyst after confirmation of cyst by aspiration; trocar was removed, contents aspirated with suction canula. Two $5 \mathrm{~mm}$ working ports were created on both sides at the level of umbilicus, in the mid clavicular line. After the inspection of the pelvis, ovaries, upper abdomen, omentum, liver and diaphragmatic surfaces for any growths or other signs of malignancy, the cyst contents were aspirated under vision with $5 \mathrm{~mm}$ suction cannula (Figure 2); once the capsule was opened, the laparoscope was introduced inside the cyst and interior of the capsule was examined for any suspicious areas. The management of the ovarian cysts included aspiration of the fluid content and cystectomy or salphingo- oophorectomy, depending on the patient's age, obstetric history and desire of future fertility.

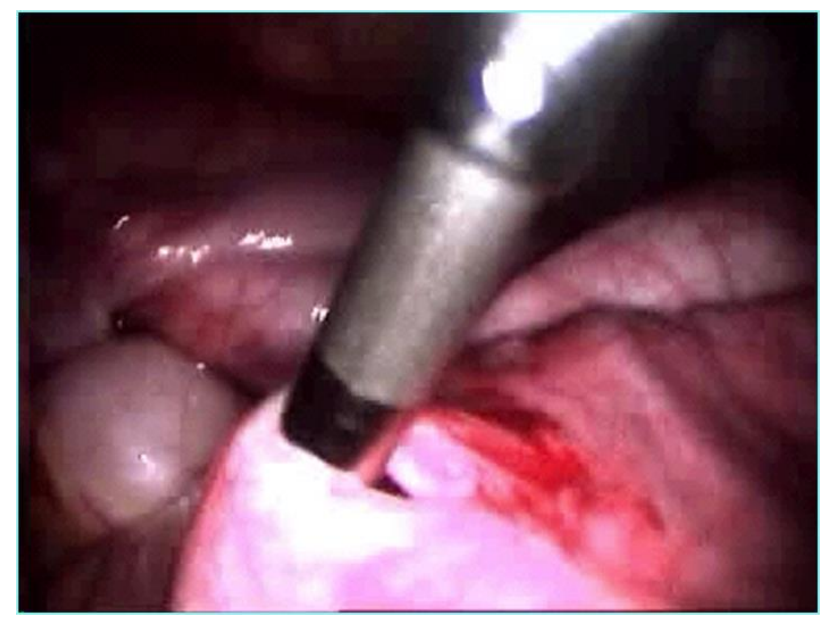

Figure 2: Aspiration of cyst by suction under vision.

In ovarian cystectomy, capsule was stripped from the ovarian stroma using two graspers for traction and counter traction. Bipolar forceps were used to coagulate the bleeding vessels at the base of capsule. In patients in whom ovary and tube could not be preserved, salphingooophorectomy was done. All the cysts were removed through umbilical port after enlarging the incision 1 to $1.5 \mathrm{~cm}$. We extracted ovarian cysts without endobags.

After the tissue was removed, the abdominal and pelvic cavities were thoroughly irrigated with copious amount of normal saline. All patients were discharged on 2 nd postoperative day.

\section{RESULTS}

The mean age of the patients was 33 (range 16-50 years). 1 patient was in pediatric age group ( $<18$ years), 9 patients were premenopausal. Seven patients presented with pain abdomen, 3 patients with abdominal distension and discomfort (Table 1).

Table 1: Common symptoms of patients with large ovarian cysts.

\begin{tabular}{|ll|}
\hline Symptoms & Patients (n) \\
\hline Abdominal pain & 07 \\
\hline Abdominal distension, discomfort & 03 \\
\hline Total & 10 \\
\hline
\end{tabular}


The average maximum diameter of the ovarian cysts was $14.75 \mathrm{~cm}$ (range 10-22 cm). The patients underwent cystectomy or adnexectomy, depending on each patient's age and obstetric history (Table 2). The mean duration of the operation was $80 \mathrm{~min}$ (ranged from 60 to 130 minutes). The postoperative hospital stay was 2 days. No intraoperative complications occurred, and the hospital course of all patients was uncomplicated.

Table 2: Type of laparoscopic surgery.

\begin{tabular}{|ll|}
\hline Laparoscopic cystectomy & Patients (n) \\
\hline Laparoscopic oophorectomy & 8 \\
\hline Laparoscopic salphingo-oophorectomy & 1 \\
\hline Total & 10 \\
\hline
\end{tabular}

All patients had benign ovarian cysts (Table 3 ). The most common histopathologic pattern was that of a serous cystadenoma. Nine patients were operated electively and 1 had adnexal torsion. There were no complications. The blood loss in all the procedures was minimal. The postoperative recovery was uneventful in all women. The patients did not report any problems during follow-up and the clinical examination findings were normal in all up to 9 months after discharge.

Table 3: Histopathology of the ovarian cysts.

\begin{tabular}{|ll|}
\hline Serous cystadenoma & Patients (n) \\
\hline Mucinous cystadenoma & 8 \\
\hline Total & 2 \\
\hline
\end{tabular}

\section{DISCUSSION}

Operative laparoscopy is regarded today as the gold standard for the surgical treatment of ovarian cysts. Large ovarian cysts, however, continue to be treated by laparotomy. This is mainly due to technical difficulties and the possibility of malignancy. The safety of laparoscopic management of benign adnexal masses has been amply demonstrated. The procedure is associated with reduced operative blood loss, fewer postoperative complications, shorter hospitalization, less pain and earlier recovery compared with laparotomy. ${ }^{3}$

Some surgeons limited laparoscopic surgery to ovarian cyst of size less than $10 \mathrm{~cm} \cdot{ }^{4-7}$ For apparently benign, extremely large ovarian cysts, only few surgeons advocate laparoscopic management. ${ }^{6-12}$, Salem reported, 15 cases of large benign ovarian cysts reaching above the level of the umbilicus, which were managed laparoscopically. ${ }^{13}$

One major concern with laparoscopic management of a large ovarian cyst is the possibility of cutting into a malignant neoplasm. This may cause intraperitoneal spillage and trocar site implantation of malignant cells. The possible adverse effect of operative spillage is still controversial. Maiman et al have reported that surgical rupture may unfavorably influence prognosis. ${ }^{14}$ However, this has not been confirmed by others using multivariate analysis. In multivariate analysis of stage 1 cancer, factors that influenced the rate of relapse were tumor grade, dense adhesions and ascites and intraoperative spillage demonstrated no adverse effect on prognosis. ${ }^{15}$ Nevertheless, a serious attempt should be made to avoid spillage as much as possible and thorough wash should be given at the end of the procedure.

Port-site metastasis after laparoscopic removal of malignant adnexal tissue is another reported complication, with a reported incidence of $1-16 \% .{ }^{16,17}$ Extraction of material in endobags is unanimously accepted, however, we followed strict criteria for preoperative evaluation and on slightest suspicion of nature of ovarian cysts, laparotomy was performed. ${ }^{7,18,19} \mathrm{We}$ aspirated the content of the cyst completely by putting 5 $\mathrm{mm}$ trocar directly in to the extremely large cyst and in rest of the patients we aspirated under vision. This technique is similar to the one used by Gogh et al. ${ }^{20} \mathrm{We}$ extracted ovarian cysts without endobags and post operative outcome was not affected. There is no absolute certainty of preventing spillage even with the endobag, since not all endoscopic bags available are of a sufficient quality. The risk of rupture of the various endobags examined differed significantly. ${ }^{21}$

Present experience shows that, with proper patient selection, laparoscopy can be done in a selected group of patients with benign large ovarian cysts.

\section{CONCLUSION}

With proper patient selection, the size of an ovarian cyst should not pose a problem for laparoscopic surgery.

\section{ACKNOWLEDGMENTS}

Authors would like to all the patients, colleagues and the operation theatre technicians, nurses and assistants.

\section{Funding: No funding sources \\ Conflict of interest: None declared \\ Ethical approval: Not required}

\section{REFERENCES}

1. Shindholimath VV, Jyoti SG, Patil KV, Ammanagi AS. Laparoscopic Management of Large Ovarian Cysts at a Rural Hospital. J Gynecol Endosc Surg. 2009;1(2):94-97.

2. Yuen PM, Yu KM, Yip SK, Lau WC, Rogers MS, Chang A. A randomized prospective study of laparoscopy and laparotomy in the management of benign ovarian masses. Am J Obstet Gynecol. 1997;177:109-14. 
3. Eltabbakh GH, Charboneau AM, Eltabbakh NG. Laparoscopic surgery for large benign ovarian cysts. Gynecol Oncol. 2008;108:72-6.

4. Eltabbakh G. laparoscopic surgery for large ovarian cysts-review trends. Gynecol Oncol 2016;2:109.

5. Gamal E. Laparoscopic surgery for large ovarian cysts-review. Curr Trends Gynecologic Oncol. 2016;1:3

6. Paul PG, Chopade G, Patil S, Das T, Thomas M, Garg R. Should we manage large ovarian cysts laparoscopically? J Gynecologic Surg. 2016;32(5):251-6.

7. Lin P, Falcone T, Tulandi T. Excision of ovarian dermoid cyst by laparoscopy and by laparotomy. Am J Obstet Gynecol. 1995;173:769-71.

8. Quinlan DK. The laparoscopic management of large ovarian cysts. J Obstet and Gynecol India. 2010;60(2):152-6.

9. Amos NN, Brodbent JAM, Hill NCW, Magos AL. Laparoscopic "oophorectomy-in-a-bag" for removal of ovarian tumors of uncertain origin. Gynecol Endoscop. 1992;1:85-9.

10. Stitely ML. Laparoscopic removal of a large ovarian mass utilizing planned trocar puncture. JSLS. 2012;16(1):148-150.

11. Vlahos NF, Iavazzo C, Marcopoulos MC. Laparoscopic management of large ovarian cysts. Surg Innov. 2012;19(4):370-4.

12. Machida H, Koyasu Y, Yamada M, Nishio M, Yamamoto K. Does tumor size limit application of laparoscopic surgery to ovarian tumors?. Gynecology and Minimally Invasive Therapy. 2016 Nov 30;5(4):156-60.

13. Salem HA. Laparoscopic excision of large ovarian cysts. J Obstet Gynaecol Res. 2002;28:290-4.

14. Maiman M, Seltzer V, Boys J. Laparoscopic excision of ovarian neoplasm subsequently found to be malignant. Obstet Gynecol. 1991;77:563-5.
15. Dembo AJ, Davy M, Stenwick AE. Prognostic factors in patients with stage 1 epithelial ovarian cancer. Obstet Gynecol. 1990;74:263.

16. Magrina JF. Laparoscopic surgery for gynecologic cancer. Clin Obstet Gynecol. 2000;43:619-40.

17. Kruitwagen RF, Swinkels BM, Keyser KGG, Doesburg WH, Schijf CPT. Incidence and effect on survival of abdominal wall metastases at trocar or puncture sites following laparoscopy or paracentesis in women with ovarian cancer. Gynecol Oncol. 1996;60:233-7.

18. Campo S, Garcea N. Laparoscopic conservative excision of ovarian dermoid cysts with and without an endobag. J Am Assoc Gynecol Laparosc. 1998;5:165-70.

19. Teng FY, Muzsnai D, Perez R, Mazdisnian F, Ross A, Sayre JW. A comparative study of laparoscopy and colpotomy for the removal of ovarian dermoid cysts. Obstet Gynecol. 1996;87:1009-13.

20. Goh SM, Yam J, Loh SF, Wong A. Minimal access approach to the management of large ovarian cysts. Surg Endosc. 2007;21:80-3.

21. Wallwiener D, Diel IJ, Sohn C, Grischke EM, Brandsch R, Kurek $\mathrm{R}$ et al. Laparoscopy in (apparently) benign ovarian tumors between benefit and catastrophy and the deceptive safety of laparoscopic lap sacs. Zentralblatt fur Gynakologie. 1996;118:53-61.

Cite this article as: Sidhmalswamy AG,

Ghongdemath JS. Laparoscopic management of large benign ovarian cysts. Int J Reprod Contracept Obstet Gynecol 2018;7:277-80. 